\title{
UNILATERAL THALAMIC VENOUS INFARCT- A RARE CASE REPORT
}

Pramod Shaha1, Kulamani Sahoo², Dhruv Aggarwal ${ }^{3}$, Pearl Aggarwal4, Varun Goyal ${ }^{5}$

1 Professor, Department of Radiodiagnosis, Krishna Institute of Medical Sciences, Karad, Maharashtra.

2 Professor and HOD, Department of Radiodiagnosis, Krishna Institute of Medical Sciences, Karad, Maharashtra.

3Junior Resident, Department of Radiodiagnosis, Krishna Institute of Medical Sciences, Karad, Maharashtra.

4Intern, SGT Medical College, Hospital and Research Institute, Gurugram, Haryana.

5Junior Resident, Department of Radiodiagnosis, Krishna Institute of Medical Sciences, Karad, Maharashtra.

HOW TO CITE THIS ARTICLE: Shaha P, Sahoo K, Aggarwal D, et al. Unilateral thalamic venous infarct- a rare case report. J. Evolution Med. Dent. Sci. 2018;7(06):807-808, DOI: 10.14260/jemds/2018/183

\section{CASE PRESENTATION}

A 17-year-old female patient with no significant premorbidities, addictions or family history of hypercoagulable diseases presented with Headache on and off since 2 months and 2 episodes of Vomiting from past 2 days for which she was admitted to our hospital. On examination, Pulse Rate- $90 \mathrm{bpm}$; Blood Pressure- 106/72 mmHg; Body Temperature- 98.6 $\mathrm{F}$. CNS examination was normal.

MRI Brain with contrast was done, which revealed right thalamic high signal intensity suggesting oedema on T2 fluid attenuated inversion recovery (FLAIR) image (Figure 1A) and patchy areas of diffusion restriction noted in the same region (Figure 1B). On SWI image, deep cerebral veins and straight sinus had low signal intensity (Figure 2A). On MR Contrast Venogram, Filling defect (arrow) noted in the region of straight sinus indicating thrombosis (Figure 2B).

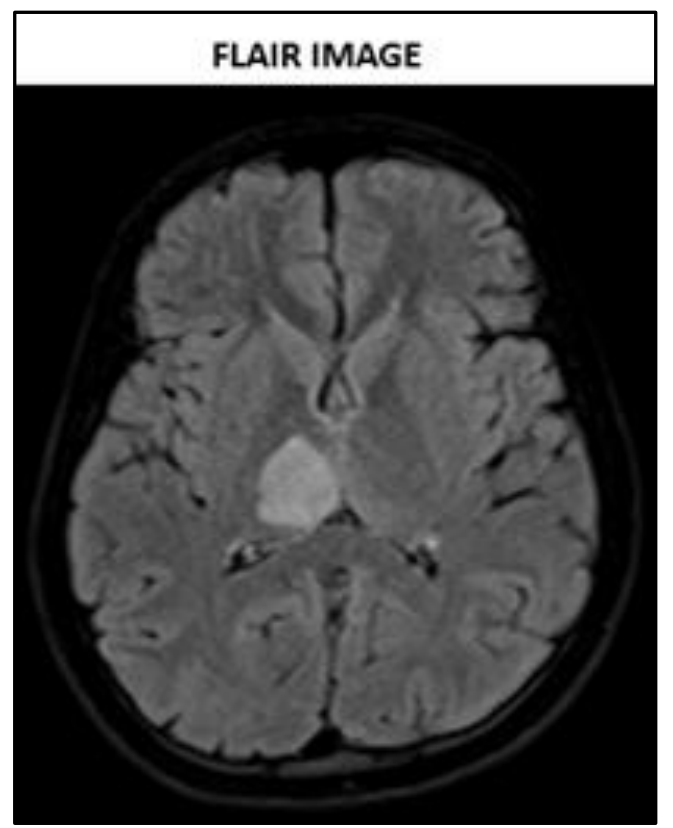

Figure 1A. T2 Fluid Attenuated Inversion Recovery (FLAIR) Imaging Study of Brain MRI showed Right Thalamic High Signal Intensity

'Financial or Other Competing Interest': None.

Submission 19-11-2017, Peer Review 06-01-2018,

Acceptance 13-01-2018, Published 05-02-2018.

Corresponding Author:

Dhruv Aggarwal,

Department of Radiodiagnosis,

Krishna Institute of Medical Sciences,

Karad-415110, Maharashtra.

E-mail: dhruvandrazer2003@gmail.com

DOI: $10.14260 /$ jemds $/ 2018 / 183$

(c) $(1)$

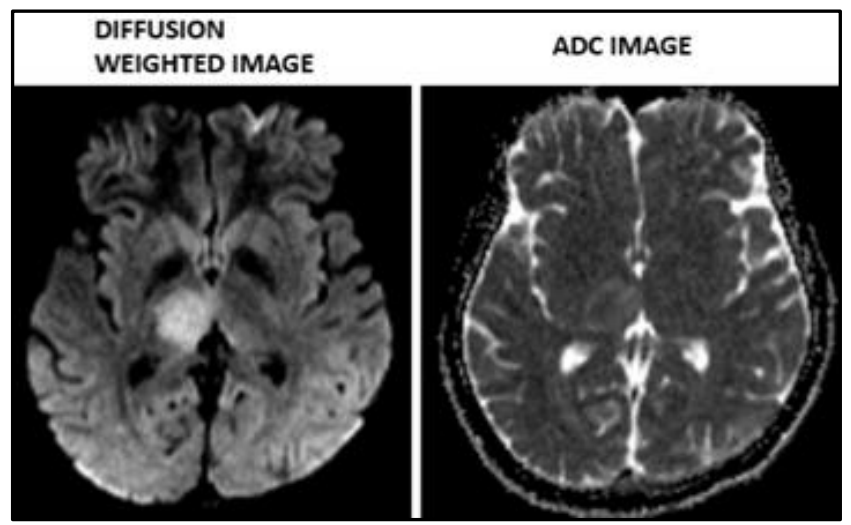

Figure 1B. Patchy Areas of Diffusion Restriction NotedHyperintense on Diffusion Weighted Image and Hypointense on ADC Image

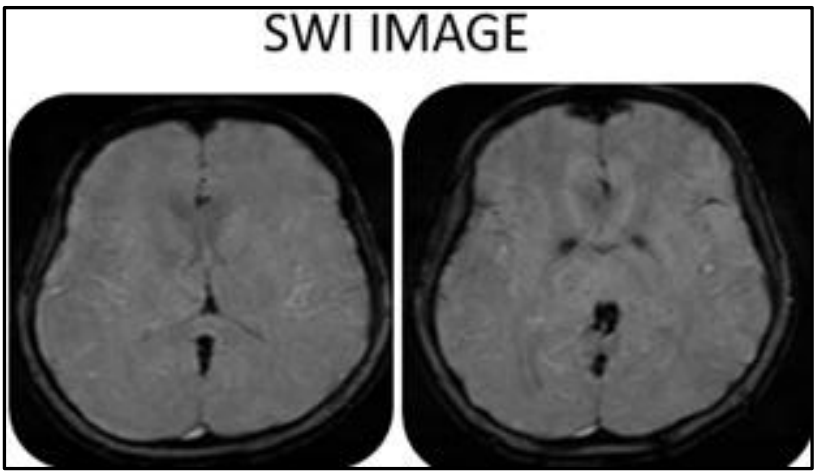

Figure 2A. Deep Cerebral Veins and Straight Sinus have Low Signal Intensity on SWI (Susceptibility Weighted Image)

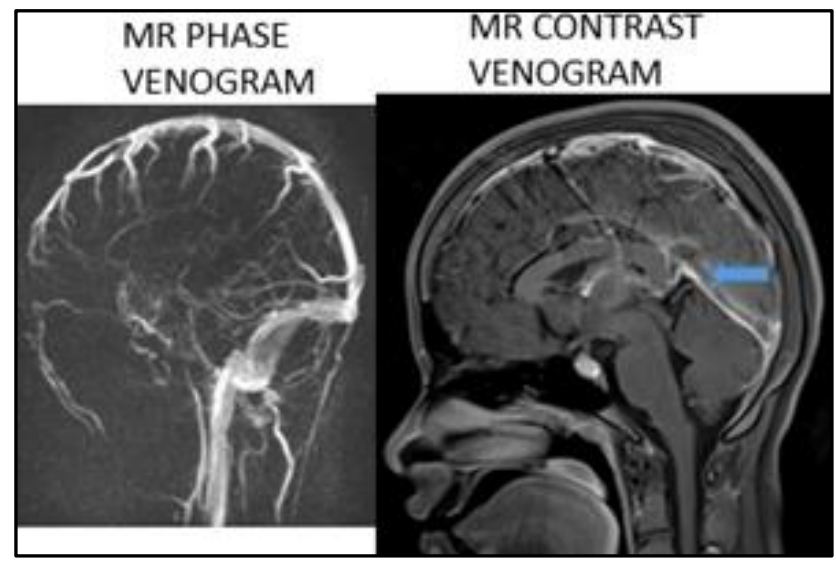

Figure 2B. On MR Phase Venogram, Straight Sinus is not visualised with Inadequate Visualisation of Deep Venous System. On MR Contrast Venogram, Filling Defect (Arrow) noted in the Region of Straight Sinus 


\section{DIFFERENTIAL DIAGNOSES}

- Neoplastic (Glioma).

- Metabolic Diseases.

- Encephalitis.

- Venous infarct.

\section{CLINICAL DIAGNOSIS}

Patient presented with Headache on and off since 2 months and 2 episodes of Vomiting in the past 2 days. Clinical symptoms were non-specific and diagnostically challenging.

\section{PATHOLOGICAL DISCUSSION}

- $\quad$ Cerebral venous sinus thrombosis (CVST) usually affects young-to-middle aged groups.

- Cerebral vein thrombosis arises from either of two mechanisms, one being an ischaemic nerve injury following venous oedema caused by a thrombosis and the other being an intracranial hypertension due to the decrease of CSF absorption following a venous occlusion. ${ }^{1}$

Of the various disease entities affecting the deep gray matter region, the basal ganglia and thalamus are of special interest. These being paired structures are symmetrically affected most often as seen in various conditions such as toxic poisoning, metabolic abnormalities and neurodegeneration. ${ }^{2}$

\section{MANAGEMENT OF DISCUSSION}

- Radiologic findings are essential for the diagnoses of cerebral venous thrombosis.

- Arterial and venous infarction both can present with hypo- and hyper-intensity on T1- and T2-weighted images respectively; however, DWI and fluid-attenuated inversion recovery (FLAIR) sequences can differentiate the two. ${ }^{2}$ Arterial infarction is seen to have restricted diffusion, while in venous infarction there is enhanced diffusion and cytotoxic oedema along with vasogenic oedema, which in turn adds to the patchy areas of restricted and enhanced diffusion. ${ }^{2}$ Hence, in an arterial infarct early changes will be seen in DWI, but not in FLAIR. ${ }^{2}$ Diffusion-weighted imaging may show very minimal or may be normal, while early abnormalities in FLAIR in venous infarct suggesting that the underlying pathology in venous infarct is vasogenic oedema rather than cytotoxic injury as seen in arterial infarcts. ${ }^{2}$
- In the majority of cases of deep internal cerebral venous thrombosis, the thalamus is affected bilaterally and venous hypertension by thrombosis causes parenchymal oedema or venous infarction and may sometimes cause venous haemorrhage. ${ }^{1}$ Because both thalami drain into the vein of Galen and straight sinus, bilateral thalamic involvement is frequently encountered in internal CVT. ${ }^{3}$

- The objectives of antithrombotic treatment in DCVT include recanalisation of the sinus or vein, and prevention of propagation of the thrombus. ${ }^{1}$ Outcome of CVST patients may vary from complete recovery to permanent neurological deficits with varying presentation of the natural course of the disease. 4

- Unilateral venous thalamic infarct is a rare entity and should be considered in the differential diagnosis of unilateral thalamic FLAIR hyperintensity in an appropriate clinical situation. A unilateral lesion shows better prognosis than a bilateral one; hence, a quick diagnosis and treatment are needed. ${ }^{1}$

\section{FINAL DIAGNOSIS}

Unilateral thalamic venous infarct affecting the right thalamus.

\section{REFERENCES}

[1] Van den Bergh WM, van der Schaaf I, van Gijn J, et al. The spectrum of presentations of venous infarction caused by deep cerebral vein thrombosis. Neurology 2005;65(2):192-6.

[2] Crombé D, Haven F, Gille M, et al. Isolated deep cerebral venous thrombosis diagnosed on CT and MR imaging. A case study and literature review. JBR-BTR 2003;86(5):257-61.

[3] Herrmann KA, Sporer B, Yousry TA, et al. Thrombosis of the internal cerebral vein associated with transient unilateral thalamic edema: a case report and review of the literature. Am J Neuroradiol 2004;25(8):1351-5.

[4] Chung SW, Hwang SN, Min BK, et al. Unilateral thrombosis of deep cerebral vein associated with transient unilateral thalamic edema. J Cerebrovasc Endovasc Neurosurg 2012;14(3):233-6. 